\title{
KAJIAN KERENTANAN MASYARAKAT PESISIR TERHADAP DAMPAK PERUBAHAN IKLIM DI KABUPATEN LOMBOK BARAT DENGAN MENGGUNAKAN PENDEKATAN PARTISIPATIF
}

\author{
Vulnerability Assessment Coastal Communities Against Climate Change Impacts in West \\ Lombok regency Using Participatory Approaches
}

\section{Andi Chairil Ichsan}

Program Studi Kehutanan Universitas Mataram

JI Majapahit No 62, Mataram, NTB

Email ; andi.foresta@unram.ac.id

\begin{abstract}
This study is an attempt to assess the vulnerability of coastal communities to climate change in a participatory way by assessing exposure, sensitivity and capacity of communities in ten coastal villages of western Lombok district in the face of various impacts climate change. The method of study was adopted from the PRA (Participatory Rural Appraisal) method with adjustments to coastal and marine context contexts called Indonesian climath adaptation tools for coastal habitat (I-CATCH). he results of this study indicate that the villages that become the object of research have a middle and high degree of vulnerability. The complexity of the problems felt by the community due to changes in seasonal patterns that occur, especially on aspects of livelihood and social environment. On the other hand, the capacity of people in dealing with the symptoms and impacts of climate change that is quite extreme is still very limited. Local adaptation strategies are needed with a focus on two main aspects: capacity building and developing of disaster management activities.
\end{abstract}

Keywords: Vulnerability, Coastal Community, Climate Change, Participatory

\begin{abstract}
Abstrak
Kajian ini merupakan upaya untuk menilai tingkat kerentanan (vulnerability) masayarakat pesisir terhadap perubahan iklim secara partisipatif, dengan cara mengkaji tentang paparan (exposure), kepekaan (sensitivity) dan kemampuan adaptasi (kapasitas) masyarakat di sepuluh desa pesisir Kabupaten Lombok Barat dalam menghadapi berbagai dampak perubahan iklim. Metode kajian diadopsi dari metode PRA (Participatory Rural Appraisal) dengan penyesuaian-penyesuaian untuk konteks kawasan pesisir dan kelautan yang disebut Indonesian Climath Adaptation Tools for Coastal Habitat (I-CATCH). Hasil kajian ini menunjukan bahwa desa-desa yang menjadi objek penelitian memiliki tingkat kerentanan yang sedang hingga tinggi. Adanya kompleksitas permasalahan yang dirasakan oleh masyarakat akibat perubahan pola musim yang terjadi, khususnya pada aspek penghidupan dan lingkungan sosialnya. Di sisi lain, kapasitas masyarakat dalam mengahdapi gejala dan dampak perubahan iklim yang cukup ekstrim dirasakan masih sangat terbatas. Dibutuhkan strategi adaptasi ditingkat lokal dengan fokus pada dua aspek utama yaitu penguatan kapasitas dan pemantapan kegiatan penanggulangan bencana.
\end{abstract}

Kata Kunci : Kerentanan, Masyarakat Pesisir, Perubahan Iklim, Partisipatif 


\section{Pendahuluan}

Perubahan iklim merupakan fenomena yang tidak bisa dipungkiri dan telah memberikan dampak pada kehidupan masyarakat Nusa Tenggara Barat (NTB). Beberapa indikasi terjadinya perubahan iklim di NTB, antara lain: musim hujan yang berlangsung lebih pendek dengan volume yang lebih besar dan meningkatnya frekuensi cuaca ekstrim, membuat pertumbuhan tanaman pangan di NTB menjadi terganggu (Butler dkk. 2009).

Kabupaten Lombok Barat termasuk wilayah yang beriklim tropis, dengan dua musim, yaitu musim kemarau yang berlangsung antara bulan april hingga agustus, dan musim hujan antara bulan september hingga maret dengan temperatur/suhu udara pada tahun 2010 rata - rata berkisar antara $23,91{ }^{\circ} \mathrm{C}$ sampai $31,94{ }^{\circ} \mathrm{C}$ dan suhu maksimum terjadi pada bulan april dengan suhu $32,90{ }^{\circ} \mathrm{C}$ serta suhu minimum $22,80{ }^{\circ} \mathrm{C}$ terjadi pada bulan juli. kelembaban udara maksimum terjadi pada bulan Mei sebesar $85 \%$ sedangkan kelembaban minimum terjadi pada bulan Agustus sebesar 79\%. Berdasarkan beberapa studi diwilayah Kabupaten Lombok Barat, saat ini kondisi ikim di kabupaten lombok barat sudah mengalami perubahan, baik dari intensitas, frekuensi maupun polanya. Dengan kondisi demikian, wilayah pesisir Kabupaten Lombok Barat merupakan salah satu kawasan yang cukup potensial menerima dampak dari perubahan tersebut.

Kajian ini bertujuan untuk menilai tingkat kerentanan (vulnerability), dengan cara menilai atau mengkaji tentang paparan (exposure), kepekaan (sensitivity) dan kemampuan adaptasi (kapasitas) masyarakat dalam menghadapi berbagai gejala dan dampak perubahan iklim.

\section{Metode}

Metode kajian diadopsi dari kajian partisipatif PRA (Participatory Rural Appraisal) dengan penyesuaian-penyesuaian untuk konteks kawasan pesisir dan kelautan yang disebut Indonesian Climath Adaptation Tools for Coastal Habitat (I-CATCH) (Siregar 2012). Dengan pendekatan tersebut, peneliti membantu masyarakat menilai sendiri tingkat kerentanan mereka terhadap dampak perubahan iklim dan selanjutnya menggunakan informasi yang telah digali untuk membangun rencana adaptasi masyarakat. Pengumpulan data dalam penelitian ini menggunakan kombinasi teknik observasi, studi literatur dan diskusi kelompok terfokus. Informan Penelitian ini dipilih dengan menggunakan teknik Purposive sampling berdasarkan karakteristik yang dikembangkan oleh Bungin (2003) yaitu informan merupakan orang yang menguasai dan memahami data, informasi, ataupun fakta dari suatu objek yang diteliti. Selanjutnya data data yang terkumpul di analisis secara deskriptif. Analisis deskriptif didefinisikan sebagai metode yang dirancang untuk menggambarkan informasi tentang keadaan yang nyata sekarang atau sementara berlangsung (Sevilla, 1993).

Adapun tahapan tahapan yang dilakukan dalam kajian ini diuraikan sebagai sebagai berikut :

Tabel 1. Tahapan pelaksanaan I-CATCH

Table 1. Phase of the I-CATCH

\begin{tabular}{lll}
\hline Tahap 1. Identifikasi Profil & & Sketsa desa \\
Masyarakat & & - Kalender musim \\
& & - Sejarah penghidupan masyarakat \\
\hline Tahap 2. Mengenali kondisi iklim & $\bullet$ Pola iklim \\
& & $\bullet$ Kondisi cuaca \\
& & - Sejarah kejadian \\
\hline Tahap 3. Mengenali masalah & $\bullet$ Mengenali dampak dan identifikasi masalah \\
\hline
\end{tabular}




\begin{tabular}{|c|c|}
\hline dampak iklim & \\
\hline $\begin{array}{l}\text { Tahap 4. Mengkaji kemampuan } \\
\text { adaptasi masyarakat }\end{array}$ & - Mengkaji kemampuan adaptasi masyarakat \\
\hline $\begin{array}{l}\text { Tahap 5. Penilaian tingkat } \\
\text { kerentanan }\end{array}$ & $\begin{array}{l}\text { - Pemaparan narasumber dari DKP Lombok Barat } \\
\text { - Peserta melakukan penilaian }\end{array}$ \\
\hline $\begin{array}{l}\text { Tahap 6. Menyusun rencana } \\
\text { adaptasi masyarakat/desa }\end{array}$ & $\begin{array}{l}\text { - Menentukan masalah yang utama } \\
\text { - Menetapkan tujuan } \\
\text { - Memetakan kekuatan, kelemahan, peluang dan } \\
\text { hambatannya } \\
\text { - Menentukan siapa, kapan, tahapan kegiatan, } \\
\text { bersama dengan pihak mana kegiatan } \\
\text { dilaksanakan dan apa dukungan yang diharapkan } \\
\text { ada. }\end{array}$ \\
\hline
\end{tabular}

Sumber : Indonesia Climath Adaptation Tools For Coastal Habitat (I-CTACH) (2012)

Proses kajian kerentanan ini tersebar pada dua kecamatan yang memiliki wilayah pesisir Kabupaten Lombok Barat, yaitu Kecamatan Lembar dan Kecamatan Sekotong, dengan mengambil 10 desa dalam dua kecamatan menjadi sampelnya. Masyarakat di desa-desa yang menjadi objek penilaian setidaknya memiliki lima sumber penghidupan utama, yakni sebagai nelayan, petani tambak, petani garam, pedagang, petani dan peternak. Lelaki dan perempuan di beberapa wilayah kajian ini saling berbagi tanggung jawab dalam melaksanakan kegiatan mata pencaharian. Nelayan dan menambak dikerjakan oleh laki-laki, sementara untuk pedagang dan pemidang ikan sebagian besar dilakukan oleh perempuan.

\section{Hasil dan Pembahasan}

Hasil kajian ini memberikan gambaran bahwa masyarakat desa yang berada diwilayah kajian, menganggap telah terjadi perubahan pada kondisi cuaca di desa, khususnya berkenaan dengan kondisi perairan laut. Kondisi musim yang berubah tersebut kemudian menimbulkan berbagai dampak baik terhadap kondisi sumber daya alam, harta benda, infrastruktur, dan lain-lain maupun bagi kehidupan masyarakat. Dampak yang dimaksud diantaranya adalah :

(1) Meningkatnya suhu udara menyebabkan turunnya kualitas dan kuantitas beberapa sumberdaya di desa, beberapa indikasinya yaitu pernah terjadi kekeringan dan kesuburan tanah menurun, tanaman petani banyak yang rusak. Begitu juga dengan berbagai ikan yang makin lama makin berkurang hingga saat ini. Pada penghidupan masyarakat, pendapatan kian menurun dan timbul berbagai macam penyakit seperti malaria, diare, flu, batuk, pilek dan sesak nafas.

(2) Kondisi suhu di darat tersebut berbanding terbalik dengan suhu laut yang makin menurun. Dinginnya temperatur di dalam perairan menyebabkan kurangnya ikan, baik jenis maupun jumlahnya.

(3) Kondisi hujan yang semakin tidak teratur waktu mulai dan berakhirnya, serta durasinya yang makin menurun telah berdampak pada menurunnya ketersediaan air didesa baik untuk irigasi maupun air bersih. Tanaman padipun banyak terkena hama. Kondisi ini berdampak pula kepada kehidupan masyarakat desa, yaitu nelayan menjadi sulit menebak waktu yang tepat untuk turun melaut. Jikapun memberanikan diri ke laut, tidak sampai ke tengah. Begitu pula di darat, ketika tidak bisa melaut, 
masyarakat yang beralih profesi menjadi petani juga sulit memperkirakan musim tanam dan jenis komoditas yang hendak ditanam. Kondisi ini kemudian berujung pada terjadinya gagal panen.

(4) Kecepatan angin yang semakin meningkat berdampak pada banyaknya pepohonan tumbang, rumah-rumah di pesisir rusak berat, bahkan pondok-pondok nelayan terseret ke laut. Tanaman di sawah dan ladangpun rusak. Selain itu, khususnya bagi nelayan, waktu melaut jadi semakin pendek dan banyak nelayan yang hilang, bahkan meninggal di tengah laut.

(5) Sama halnya dengan tinggi gelombang, tetap sama dengan waktu-waktu sebelumnya bahkan intensitasnya cenderung lebih kecil. namun jika gelombang cukup pasang dapat mengakibatkan abrasi dan rob di kawasan pesisir pantai

Uraian mengenai dampak perubahan kondisi iklim diatas menjadi dasar kajian kerentanan ini dilakukan. Salah satu faktor yang di analisis dalam kajian tersebut yaitu mengidentifikasi tingkat paparan perubahan kondisi iklim yang terjadi di dimasing masing desa. Dalam menilai paparan perubahan kondisi iklim tersebut, perlu diuraikan terlebih dahulu komponen perubahan kondisi iklim dan cakupannya bagi kehidupan masyarakat. Secara detail mengenai analisa tingkat paparan dapat dilihat pada tabel berikut :

Tabel 2. Tingkat Paparan Desa

Table 2. Village Exposure Rates

\begin{tabular}{|c|c|c|c|}
\hline Nilai & Pengertian & Penjelasan & $\begin{array}{c}\text { Jumlah } \\
\text { Desa }\end{array}$ \\
\hline $\begin{array}{l}\text { RENDAH } \\
\text { (1) }\end{array}$ & $\begin{array}{l}\text { Sebagian kecil } \\
\text { sumberdaya alam } \\
\text { dipengaruhi oleh } \\
\text { perubahan kondisi } \\
\text { iklim atau beberapa } \\
\text { individu saja yang } \\
\text { sumber } \\
\text { penghidupannya } \\
\text { bergantung pada } \\
\text { kondisi iklim }\end{array}$ & $\begin{array}{l}\text { Masyarakat Desa mengalami: } \\
\text { - Masa berlangsungnya angin musim dan } \\
\text { musim penghujan tetap sama atau } \\
\text { hanya bergeser sedikit, tanda-tanda } \\
\text { datangnya musim tetap sama, } \\
\text { kemampuan masyarakat menduga } \\
\text { musim masih dapat diandalkan } \\
\text { - Sedikit sumber penghidupan/mata } \\
\text { pencaharian masyarakat tsb bergantung } \\
\text { pada kondisi iklim } \\
\text { - Kejadian cuaca buruk yang merusak } \\
\text { harta benda dan keselamatan jiwa } \\
\text { jarang teriadi pada } 10 \text { hari terakhir } \\
\text { - Tidak ada atau hanya sedikit lahan } \\
\text { yang tergenang air laut karena pasang } \\
\text { tinggi atau kenaikan permukaan laut }\end{array}$ & 1 Desa \\
\hline $\begin{array}{l}\text { SEDANG } \\
\text { (2) }\end{array}$ & $\begin{array}{l}\text { Sekitar setengah } \\
\text { masyarakat atau } \\
\text { sumberdaya alam } \\
\text { dipengaruhi oleh } \\
\text { perubahan kondisi } \\
\text { iklim dan atau } \\
\text { setengah penduduk } \\
\text { desa yang sumber } \\
\text { penghidupannya } \\
\text { bergantung pada } \\
\text { kondisi iklim }\end{array}$ & $\begin{array}{l}\text { Masyarakat pada desa tersebut } \\
\text { mengalami: } \\
\text { - Masa berlangsungnya angin musim } \\
\text { penghujan berubah, bergeser beberapa } \\
\text { hari hingga } 1 \text { bulan, tanda tanda } \\
\text { datangnya musim sebagian tidak sama } \\
\text { lagi, kemampuan menduga musim } \\
\text { hanya sebagian yang bisa diandalkan. } \\
\text { - Sebagian sumber penghidupan/mata } \\
\text { pencaharian masyarakat tsb bergantung } \\
\text { pada kondisi iklim } \\
\text { - Kejadian cuaca buruk yang merusak } \\
\text { harta benda dan keselamatan jiwa }\end{array}$ & 1 Desa \\
\hline
\end{tabular}




\begin{tabular}{|c|c|c|c|}
\hline Nilai & Pengertian & Penjelasan & $\begin{array}{c}\text { Jumlah } \\
\text { Desa }\end{array}$ \\
\hline & & $\begin{array}{l}\text { berlangsung beberapa kali pada } 10 \\
\text { tahun terakhir } \\
\text { - Luasan lahan yang tergenang air laut } \\
\text { karena pasang tinggi atau kenaikan } \\
\text { permukaan laut sama setiap tahunnya }\end{array}$ & \\
\hline $\begin{array}{l}\text { TINGGI } \\
\text { (3) }\end{array}$ & $\begin{array}{l}\text { Sebagian } \\
\text { besar/hamper } \\
\text { seluruh SDA } \\
\text { dipengaruhi oleh } \\
\text { perubahan kondisi } \\
\text { iklim dan atau } \\
\text { hampir seluruh } \\
\text { penduduk desa } \\
\text { sumber } \\
\text { penghidupannya } \\
\text { bergantung pada } \\
\text { kondisi iklim }\end{array}$ & $\begin{array}{l}\text { Masyarakat pada desa tersebut } \\
\text { mengalami: } \\
\text { - Masa berlangsungnya angin musim } \\
\text { penghujan berubah, bergeser hingga } \\
\text { lebih dari } 1 \text { bulan, tanda tanda } \\
\text { datangnya musim seluruhnya tidak } \\
\text { sama lagi, kemampuan menduga } \\
\text { musim hanya tidak lagi dapat } \\
\text { diandalkan. } \\
\text { - Hampir seluruh sumber penghidupan/ } \\
\text { mata pencaharian masyarakat tsb } \\
\text { bergantung pada kondisi iklim } \\
\text { - Kejadian cuaca buruk yang merusak } \\
\text { harta benda dan keselamatan jiwa } \\
\text { hampir terjadi tiap tahun. } \\
\text { - Luasan lahan yang tergenang air laut } \\
\text { karena pasang tinggi atau kenaikan } \\
\text { permukaan laut bertambah setiap } \\
\text { tahunnya selama } 10 \text { tahun terakhir. }\end{array}$ & 8 Desa \\
\hline
\end{tabular}

Sumber : Indonesia Climath Adaptation Tools For Coastal Habitat (I-CTACH) (2012)

Tabel diatas mendeskripsikan bahwa tingkat paparan di masing masing desa termasuk cukup tinggi. terdapat delapan desa diwilayah kajian yang sangat merasakan dampak perubahan kondisi musim yang terjadi. Beberapa faktor penyebabnya yaitu selain karakteristik wilayah yang rentan terhadap bencana, hal tersebut juga dipengaruhi oleh jenis mata pencaharian mayoritas masayarakat di delapan desa tersebut sangat tergantung pada kondisi musim seperti sektor pertanian, perkebunan dan perikanan.

Selain informasi mengenai tingkat paparan, analisis dalam kajian ini juga difokuskan pada tingkat kepekaan masyarakat terhadap dampak perubahan iklim yang terjadi di masing-masing desa. Secara konseptual kepekaan (sensitifitas) menurut IPCC (2007) adalah sejauh mana masyarakat dan sumberdaya peka atau dapat dipengaruhi bila kondisi iklim berubah (suhu udara, penguapan). Dengan pengertian ini, kepekaan merupakan sebuah asumsi dampak berdasarkan pengalaman maupun pengetahuan yang dimiliki oleh masyarakat. Untuk membantu proses identifikasi tingkat kepekaan tersebut, dalam kajian ini digunakan tabel rentang kerentanan yang diadaptasi modul I-CTACH (Siregar 2012) dengan rincian seperti diuraikan dalam tabel berikut :

Tabel 3. Rentang kepekaan masyarakat

Table 3. Range of public sensitivity

\begin{tabular}{llcl}
\multicolumn{1}{c}{$\begin{array}{c}\text { Pengaruh perubahan iklim dan } \\
\text { cuaca buruk }\end{array}$} & Rentang Kepekaan & \\
\hline $\begin{array}{l}\text { Perubahan kondisi iklim dirasakan } \\
\text { pengaruhnya pada kegiatan }\end{array}$ & Sedikit & Cukup & Besar \\
$\begin{array}{l}\text { penghidupan (mata pencaharian) } \\
\text { masyarakat }\end{array}$ & & & \\
\hline
\end{tabular}




\begin{tabular}{|c|c|c|c|}
\hline \multirow{2}{*}{$\begin{array}{l}\text { Pengaruh perubahan iklim dan } \\
\text { cuaca buruk }\end{array}$} & \multicolumn{3}{|c|}{ Rentang Kepekaan } \\
\hline & $\begin{array}{l}\text { Beberapa } \\
\text { hari }\end{array}$ & $\begin{array}{l}\text { Setengah } \\
\text { musim }\end{array}$ & $\begin{array}{l}\text { Satu musim } \\
\text { atau lebih }\end{array}$ \\
\hline $\begin{array}{l}\text { Pengaruh perubahan kondisi iklim } \\
\text { pada kesehatan dan ketenangan jiwa } \\
\text { masyarakat }\end{array}$ & Sedikit & Cukup & Besar \\
\hline $\begin{array}{l}\text { Pengaruh perubahan kondisi iklim } \\
\text { pada SDA perikanan (tidak } \\
\text { mengakibatkan kematian/ kerusakan } \\
\text { terumbu karang, mangrove lainnya) }\end{array}$ & Sedikit & Sedang & Besar \\
\hline $\begin{array}{l}\text { Kejadian cuaca buruk yang } \\
\text { mengakibatkan kerusakan harta } \\
\text { benda dan kecelakaan } 10 \text { tahun } \\
\text { terakhir }\end{array}$ & Jarang & $\begin{array}{l}\text { Beberapa } \\
\text { kali terjadi }\end{array}$ & $\begin{array}{c}\text { Sering } \\
\text { (hampir } \\
\text { setiap tahun } \\
\text { berlangsung) }\end{array}$ \\
\hline $\begin{array}{l}\text { Pengaruh perubahan kondisi iklim } \\
\text { secara keseluruhan }\end{array}$ & RENDAH & SEDANG & TINGGI \\
\hline \multicolumn{4}{|c|}{ Sumber : Indonesia Climath Adaptation Tools For Coastal Habitat (I-CTACH) (2012) } \\
\hline \multicolumn{4}{|c|}{$\begin{array}{l}\text { Hasil analisa dengan menggunakan tabel rentang kepekaan diatas, dapat } \\
\text { memberikan penjelasan bahwa dari } 10 \text { desa yang menjadi wilayah studi, terdapat } 8 \text { desa } \\
\text { yang memiliki tingkat kepekaan tinggi, satu desa memiliki tingkat kepekaan rendah dan } \\
\text { satu desa yang memiliki tingkat kepekaan sedang. Hal ini menunjukkan bahwa sebagian } \\
\text { besar wilayah yang menjadi lokasi studi ini sangat terpengaruh terhadap perubahan } \\
\text { kondisi musim yang terjadi. }\end{array}$} \\
\hline
\end{tabular}

Hasil analisis dari tingkat paparan dan kepekaan kemudian ditabulasi dengan menggunakan matriks potensi dampak (lihat tabel 4) yang berfungsi untuk memberikan informasi apakah dampak perubahan iklim tersebut memiliki potensi dampak yang besar, sedang ataupun kecil.

Tabel 4. Matriks Potensi Dampak

Table 4. Potential Impact Matrices

\begin{tabular}{cccc}
\hline PAPARAN & \multicolumn{3}{c}{ KEPEKAAN } \\
\cline { 2 - 4 } & $\begin{array}{c}\text { Hampir tidak ada } \\
(\mathbf{1})\end{array}$ & $\begin{array}{c}\text { Sedang } \\
(\mathbf{2})\end{array}$ & $\begin{array}{c}\text { Parah/tinggi } \\
(\mathbf{3})\end{array}$ \\
\hline $\begin{array}{c}\text { Kecil hingga tidak } \\
\text { ada } \\
(\mathbf{1})\end{array}$ & Kecil & Kecil & Sedang \\
\hline $\begin{array}{c}\text { Beberapa } \\
(\mathbf{2})\end{array}$ & & & Tinggi \\
\hline $\begin{array}{c}\text { Hampir semua } \\
(3)\end{array}$ & Kecil & Sedang & Tinggi \\
\hline
\end{tabular}

Sumber : Indonesia Climath Adaptation Tools For Coastal Habitat (I-CTACH) (2012)

Kemudian, untuk memberikan informasi yang komprehensif terkait pelaksanaan kajian kerentanan masyarakat pesisir di Kabupaten Lombok Barat. Kajian ini juga melengkapi lingkup analisisnya dengan melakukan analisia kemampuan masyarakat dalam menghadapi perubahan iklim yang terjadi pada masing-masing wilayah desa. Parameternya didasarkan pada kombinasi ciri-ciri kapasitas ideal yang di konstruksikan sendiri oleh masayarakat dan disandingkan dengan kerangka acuan adaptasi ideal yang disusun dalam panduan I-ICTACH, beberapa diantaranya meliputi : 
1. Masyarakat memiliki kebersamaan kebiasaan gotong-royong, memiliki pemimpin dan beberapa orang yang bekerja untuk kepentingan desa, kebiasaan bermusyawarah membuat rencana bersama dan nilai nilai baik dalam mengelola lingkungan.

2. Masyarakat memiliki keahlian, kemampuan, dan kerja sama serta motivasi kuat untuk mengatasi perubahan kondisi iklim terhadap sumber penghidupan, diantaranya dengan mata pencaharian mengatasi masalah cuaca buruk yang mengakaibatkan kerusakan harta benda dan keselamatan jiwa.

3. Masyarakat memiliki kemampuan membangun kerjasama dan hubungan baik dengan pihak luar (LSM, swasta, pemda,) dan menyelenggarakan kerjasama kegiatan.

4. Lingkungan tempat mukim yang sehat, SDA yang beragam dan sumber air yang sehat dan cukup.

5. Memiliki pengetahuan dan pengalaman menghadapi perubahan lingkungan sebelumnya.

Hasilnya, diperoleh informasi bahwa daya adaptasi masyarakat terhadap perubahan iklim di masing masing desa yang menjadi lokasi kajian ini cukup beragam, dan di dominasi oleh daya adaptasi sedang. Hasil ini menunjukkan bahwa meskipun tingkat paparan dan kepekaan di masing masing desa cukup tinggi, namun masyarakat juga sudah mulai mempersiapkan diri menghadapi situasi tersebut, dengan melakukan berbagai upaya seperti membentuk kelompok kelompok sosial (banjar, kelompok tani, kelompok nelayan dII) untuk memperkuat relasi sosialnya. Disisi lain untuk meningkatkan perekonomiannya, masyarakat juga sudah membangun usaha-usaha alternatif agar tidak bergantung sepenuhnya pada satu sumber penghidupan saja (berdagang, Tukang, warung makan, pemandu wisata dII).

Selanjutnya proses sintesis dari aspek-aspek tersebut (tingkat paparan, kepekaan dan Kemampuan adaptasi) akan memberikan gambaran mengenai tingkat kerentanan masyarakat terhadap dampak dari perubahan kondisi iklim (pola musim), cuaca dan kejadian bencana di masing-masing desa. Hasil kajian tingkat kerentanan di kesepuluh desa yang menjadi wilayah studi ini di uraikan pada tabel berikut.

Tabel 5. Analisis Kerentanan Masyarakat di Kabupaten Lombok Barat Table 5. Community Vulnerability Analysis in West Lombok District

\begin{tabular}{cllcccc}
\hline No & Desa & Ancaman Utama & $\begin{array}{c}\text { Tingkat } \\
\text { Paparan }\end{array}$ & $\begin{array}{c}\text { Tingkat } \\
\text { Kepekaan }\end{array}$ & $\begin{array}{c}\text { Tingkat } \\
\text { Adaptasi }\end{array}$ & Kerentanan \\
\hline 1 & $\begin{array}{l}\text { Cendi } \\
\text { Manik }\end{array}$ & Banjir & Tinggi & Rendah & Sedang & Sedang \\
\hline 2 & $\begin{array}{l}\text { Sekotong } \\
\text { Barat }\end{array}$ & $\begin{array}{l}\text { Banjir Rob dan. } \\
\text { Abrasi Pantai }\end{array}$ & Sedang & Tinggi & Rendah & Tinggi \\
\hline 3 & $\begin{array}{l}\text { Sekotong } \\
\text { Tengah }\end{array}$ & Banjir Rob & Rendah & Tinggi & Sedang & Sedang \\
\hline & $\begin{array}{l}\text { Buwun } \\
\text { Mas }\end{array}$ & $\begin{array}{l}\text { Geloro (gelombang \& } \\
\text { angin yang } \\
\text { mengakibatkan } \\
\text { abrasi), } \\
\text { Banjir, } \\
\text { Longsor }\end{array}$ & Tinggi & Tinggi & Rendah & Tinggi \\
& & & & & \\
\hline
\end{tabular}




\begin{tabular}{cllllll}
\hline No & Desa & Ancaman Utama & $\begin{array}{c}\text { Tingkat } \\
\text { Paparan }\end{array}$ & $\begin{array}{c}\text { Tingkat } \\
\text { Kepekaan }\end{array}$ & $\begin{array}{c}\text { Tingkat } \\
\text { Adaptasi }\end{array}$ & Kerentanan \\
\hline 5 & Gili Gede & $\begin{array}{l}\text { Abrasi, } \\
\text { Gangguan } \\
\text { kesehatan, } \\
\text { Penerangan desa, } \\
\text { Kekeringan }\end{array}$ & Tinggi & Sedang & Tinggi & Sedang \\
\hline 6 & $\begin{array}{l}\text { Batu } \\
\text { Putih }\end{array}$ & Banjir Rob & Tinggi & Tinggi & sedang & Tinggi \\
\hline 7 & $\begin{array}{l}\text { Lembar } \\
\text { Utara }\end{array}$ & Banjir Rob & Tinggi & Tinggi & Tinggi & Tinggi \\
\hline 8 & $\begin{array}{l}\text { Lembar } \\
\text { Selatan }\end{array}$ & Banjir Rob & Tinggi & Tinggi & Sedang & Sedang \\
\hline 9 & $\begin{array}{l}\text { Labuan } \\
\text { Tereng }\end{array}$ & $\begin{array}{l}\text { Banjir Rob dan } \\
\text { kekeringan }\end{array}$ & Tinggi & Tinggi & Sedang & Sedang \\
\hline 10 & $\begin{array}{l}\text { Eat } \\
\text { Mayang }\end{array}$ & $\begin{array}{l}\text { Banjir dan angin } \\
\text { putting beliung }\end{array}$ & Tinggi & Tinggi & Sedang & Sedang \\
\hline
\end{tabular}

Sumber : Data primer diolah

Tabel diatas dapat dapat memberikan gambaran bahwa dari 10 desa yang dijadikan sebagai lokasi kajian, terdapat 4 desa yang memiliki tingkat kerentanan tinggi dan 6 desa lainnya memiliki tingkat kerentanan yang sedang. Hal ini menunjukkan bahwa perubahan kondisi iklim yang berlangsung selama ini telah menimbulkan dampak pada sistem kehidupan masyarakat, baik dari aspek infrastruktur, ekonomi dan sosial budayanya.

Situasi tersebut juga telah direspon dengan berbagai cara oleh masyarakat, baik dengan melakukan diversifikasi sumber penghidupan, maupun membentuk kelompok kelompok sosial di tingkat lokal sebagai bagian untuk memperkuat relasi mereka. Namun demikian upaya upaya tersebut juga dirasakan masih kurang optimal dalam merespon perubahan yang terjadi. Beberapa persoalan masih sering datang pada setiap perubahan kondisi iklim sehingga mengancam sistem kehidupan yang ada di masing masing desa.

Menindak lanjuti situasi tersebut, kajian ini juga memberikan ruang bagi masyarakat untuk mengidentifikasi kekuatan, kelemahan, peluang dan tantangan yang dihadapi mereka dalam merspon perubahan perubahan yang terjadi. Hasilnya, masyarakat dapat merumuskan beberapa rencana aksi yang dapat dilakukan ditingkat lokal dengan tujuan untuk meminimalisir dampak negatif dari perubahan -perubahan tersebut berdasarkan karakteristik sumberdaya di masing-masing desa. Secara umum ruang lingkup rencana aksi tersebut terfokus pada dua aspek utama, yaitu peguatan kapasitas dan penanggulangan kebencanaan. Secara detail mengenai kedua aspek tersebut dapat dilihat pada uraian dibawah ini:

\section{Penguatan kapaistas dan kelembagaan kelompok}

Kegiatan penguatan kapasitas dan penguatan kelembagaan kelompok nelayan dinilai memiliki peranan yang cukup penting bagi masyarakat dalam meningkatkan keberdayaan mereka untuk menghadapi dampak perubahan iklim. Ichsan et al (2017) mengungkapkan bahwa penguatan kelembagaan berfungsi memberikan pengaturan sistematis terkait interaksi parapihak untuk mencapai tujuan yang 
ditetapkan (efektif dan efisien). Beberapa langkah nyata yang akan diusahakan masyarakat dalam memperkuat kapasitas dan kelembagaan mereka yatiu :

a. Pelatihan SAR dan kebencanaan yang dimaksudkan agar masyarakat memiliki pemahaman terhadap konteks kebencanaan dan mampu menghindarkan diri dari ancaman bencana yang datang

b. Melakukan pemetaan partisipatif, dengan tujuan untuk memetakan daerahdaerah didesa yang dianggap rawan bencana, sehingga bisa dipikirkan langkah penanggulangannya.

c. Membentuk kelompok-kelompok wanita nelayan. kelompok ini dapat meringankan beban para nelayan dalam menghadapi masa-masa sulit ketika tidak bisa melaut akibat faktor iklim.

d. Membangun balai pertemuan kelompok. Dengan tujuan agar bisa dijadikan sebagai pusat informasi kelompok, serta sebagai tempat koordinasi dan sarana untuk pembelajaran kelompok.

e. Melakukan sosialisasi -sosialisasi terkait dengan infromasi dan pelaksanaan program yang berkaitan dengan penghidupan nelayan, serta informasi mengenai perubahan-perubahan kondisi iklim yang terjadi di desa

f. Membangun proses koordinasi dengan parapihak dalam bentuk audiensi dengan bupati, dan kepala dinas kelautan dan perikanan serta pihak lainnya yang memiliki kepentingan terhadapop sektor kelautan, dengan tujuan agar mendpatkan bantuan dana, pembinaan dan kucuran program dari para pihak untuk kepentingan nelayan yang ada didesa.

g. Membangun kerjasama lintas desa

\section{Penanggulangan kebencanaan}

a. Untuk meminimalisir dampak dari Banjir/ROB maka perlu segera dilakukan penambahan dan peninggian talud di dusun terdampak.

b. Sebagai upaya untuk mengantisipasi dampak buruk dari bertumpuknya sampah masyarakat berencana untuk mengusulkan Pembuatan tempat pembuangan sampah sementara di setiap perkampungan, kerana selama ini kondisi beberapa perkampungan di wilayah pesisir terlihat kotor dan kumuh akibat tidak adanya fasilitas pembuagan sampah yang memadai.

c. Masyarakat juga mengusulkan Pentalutan (Bronjong) di sepanjang pesisir desa, mengingat selama ini wilayah-wilayah pesisir sangat rentan terhadap ancaman banjir dan gelombang pasang

d. Untuk mengantisipasi bencana banjir kiriman, gelombang pasang dan abrasi masayarakat juga megusulkan kegiatan Penanaman pohon atau penghijauan di pegunungan dan beberapa dusun pesisir.

e. Pembangunan Transmisi Informasi Cuaca sangat diharapkan oleh masayarakat khususnya para nelayan untuk memberikan informasi yang cepat dan akurat mengenai kondisi terkini cuaca, karena selama ini masyarakat hanya mengandalkan kemampuannya secara tradisional dalam membaca kondisi cuaca dan saat ini prediksi mereka pun cenderung meleset.

Penyusunan rencana aksi tersebut harus bersinergi dengan kebijakan daerah baik ditingkat kabupaten sampai pada tingkat desa. Internalisasi rencana aksi ini kedalam sistem perencanaan kabupaten (RPJMD) dan Desa (RPJMDES) menjadi suatu keharusan untuk menjamin realisasinya dilapangan. Hal ini penting, mengingat dokumen dokumen tersebut merupakan salah satu pilihan kebijakan yang sah dan berfungsi untuk mengatur dan mengontrol aktifitas peyelengaraan pembangunan didaerah (Scot 2008; 
Dunn 2003). Dengan demikian, maka pola dan bentuk intervensi program yang akan dilakukan dapat diprediksi (kasper \& Streit 1998).

\section{Kesimpulan}

Perubahan kondisi iklim dan cuaca yang berlangsung di desa yang menjadi wilayah studi ini telah memberikan dampak sangat beragam baik secara ekologis, sosial maupun ekonomi di desa tersebut. Di sisi lain, kapasitas dan keterampilan masyarakat dalam menghadapi gejala dan dampak perubahan musim yang cukup ekstrim dirasakan masih sangat terbatas. Hal ini ditandai dengan masih tingginya tingkat kerenatanan masyarakat yang ada di masing-masing desa. Di sisi lain, berbagai upaya juga telah dilakukan masyarakat untuk mempertahankan kehidupannya. Namun demikian, upayaupaya tersebut dirasakan masih kurang optimal, Karena dampak perubahan kondisi musim diarasakan tidak sebanding dengan daya adaptasi masyarakat. Dengan demikian, dibutuhkan suatu perencanaan sistematis dan terfokus pada upaya percepatan peningkatan kapasitas masyarakat dan penanggulangan kebencanaan.

\section{Daftar Pustaka}

Butler, J., Kirono, D.G.C., Katzfey, J., and Nguyen, K. (2009) : Climate Adaptation Strategies for Rural Livelihoods in West Nusa Tenggara Province. CSIRO_AusAID report, 2009.

Bungin B. 2003. Analisis Data Penelitian Kualitatif. Jakarta: Radja Grafindo Persada.

Dunn, William N. (2003). Analisis Kebijakan Publik. Yogyakarta: Gadjah Mada University Press.

Ichsan, A. C., Soekmadi, R., Adiwibowo, S., \& Kusmana, C. (2017). Relation between Preferences Community Land Use with Conservation Village Model Development at Mount Rinjani National Park. International Journal of Sciences: Basic and Applied Research, 31(1), 375-388.

Siregar. P Raja, 2012. Indonesia Climate Adaptation Tool for Coastal Habitats. USAID IMACS : Indonesia

BMKG Stasiun Meteorologi Selaparang Mataram. (2000-2010). Data Cuaca dan Iklim di Pulau Lombok. Mataram

BPS Lombok Barat. (2012). Data Statistik Kabupaten Lombok Barat. Kabupaten Lombok Barat

IPCC, (2007) : Climate Change: The Physical Science Basis, Contribution of Working Group (WG) 1 to the Fourth Assessment Report of the (IPCC), Cambridge University Press, Cambridge, UK, and New York, 273-313.

Kasper W, Streit ME. 1998. Institutional Economics, Social Order and Policy. Edward Elgar. Cheltenham, UK. and Northampton, MA. USA.

Sevilla CG et al. 1993 Pengantar Metode Penelitian. Penerjemah; Alimudin Tuwu dan Alam Syah. Jakarta: UI Press.

Scott, W.R. (2008), Institutions and Organizations: Ideas andlnterests, $3^{\text {rd }}$ ed. Sage Publications, Los Angeles, CA. 